\title{
Effects of microtopography on spatial point pattern of forest stands on the semi-arid Loess Plateau, China
}

\author{
WeiJun ZHAO ${ }^{1,2}$, Yan ZHANG ${ }^{2}$, QingKe ZHU ${ }^{2 *}$, Wei QIN $^{3}$, ShuZhen PENG ${ }^{1}$, Ping $\mathrm{LI}^{4}$, YanMin ZHAO ${ }^{2}$, \\ Huan $M^{2}$, Yu WANG ${ }^{2}$ \\ ${ }^{1}$ Key Laboratory of Tourist Resources and Environment in Colleges and Universities of Shandong Province, Taishan University, \\ Tai'an 271021, China; \\ ${ }^{2}$ Forestry Ecological Engineering Research Center (Ministry of Education), Beijing Forestry University, Beijing 100083, China; \\ ${ }^{3}$ Department of Sedimentation, China Institute of Water Resources and Hydropower Research, Beijing 100044, China; \\ ${ }^{4}$ Key Laboratory of Forest Ecology and Environment of State Forestry Administration, Institute of Forest Ecology, Environment \\ and Protection, Chinese Academy of Forestry, Beijing 100091, China
}

\begin{abstract}
Microtopography may affect the distribution of forests through its effect on rain redistribution and soil water distribution on the semi-arid Loess Plateau, China. In this study, we investigated the characteristics of microtopography on two shady slopes (slope A, $5 \mathrm{hm}^{2}$, uniform slope; slope B, $5 \mathrm{hm}^{2}$, microtopography slope) and surveyed the height, the diameter at breast height and the location ( $x, y$ coordinates) of all selected individual trees (Robinia pseudoacacia Linn., Pyrus betulifolia Bunge, Populus hopeiensis Hu \& Chow, Armeniaca sibirica Lam., Populus simonii Carr. and Ulmus pumila Linn.) on slope A and slope B in the watersheds of Wuqi county, Shaanxi province. Subsequently, the effects of microtopography on the spatial pattern of forest stands were analyzed using Ripley's $K(r)$ function. The results showed that: (1) The maximal aggregation radiuses of the tree species on the uniform slope (slope A) were larger than $40 \mathrm{~m}$, whereas those of the tree species on the microtopography slope (slope B) were smaller than $30 \mathrm{~m}$. (2) On slope B, the spatial association of $R$. pseudoacacia with $P$. betulifolia, $A$. sibirica, $P$. simonii and $U$. pumila varied from being strongly negative to positive at microtopography scales. The spatial association of Populus hopeiensis Hu \& Chow with $U$. pumila also varied from being strongly negative to positive at microtopography scales. However, there was no spatial association between $P$. betulifolia and $P$. hopeiensis, P. betulifolia and A. sibirica, P. betulifolia and P. simonii, P. betulifolia and U. pumila, P. hopeiensis and A. sibirica, $P$. hopeiensis and $P$. simonii, A. sibirica and $P$. simonii, $A$. sibirica and $U$. pumila, and $P$. simonii and $U$. pumila. On slope $A$, the spatial association between tree species were strongly negative. The results suggest that microtopography may shape tree distribution patterns on the semi-arid Loess Plateau.
\end{abstract}

Keywords: microtopography; univariate spatial patterns; aggregation; negative association; positive association

Citation: WeiJun ZHAO, Yan ZHANG, QingKe ZHU, Wei QIN, ShuZhen PENG, Ping LI, YanMin ZHAO, Huan MA, Yu WANG. 2015. Effects of microtopography on spatial point pattern of forest stands on the semi-arid Loess Plateau, China. Journal of Arid Land, 7(3): 370-380. doi: $10.1007 /$ s40333-015-0123-z

Vegetation restoration is important for the control of soil and water loss, and has become a focus of forestry research (Zhu et al., 2012). In the process of vegetation restoration, it is crucial to select suitable tree species and vegetation configuration models based on local conditions (e.g. topography and soil moisture), especially for the Loess Plateau of China due to its fragmented topography (Yang et al., 2006; Wang et al.,
2009; Zhu et al., 2012). Rainfall is redistributed on fragmented topographies, causing differences in soil moisture (Zhao et al., 2010) and microhabitat in different topography types (Chimner and Hart, 1996; Nagamatsu and Miura, 1997; Lu et al., 2009; Zhao et al., 2010; Wang et al., 2011; Zhang et al., 2011a, b; Zhu et al., 2012).

In the 1980 s, a forestation model that matched tree

"Corresponding author: QingKe ZHU (E-mail: qingkezhu@126.com)

Received 2014-04-04; revised 2014-08-10; accepted 2014-08-18

(C) Xinjiang Institute of Ecology and Geography, Chinese Academy of Sciences, Science Press and Springer-Verlag Berlin Heidelberg 2015 
species with sites was developed in the Loess Plateau (Zhu, 1988). A conventional forestation model that used uniform planting points with the same row spacing along contours based on the site conditions of slopes was also proposed (Zou et al., 1980; Zhu et al., 2012). However, the trees planted based on the conventional forestation model developed into small old trees (Zhu et al., 2012). Recently, a forestation model based on microtopography was put forward for the Loess Plateau (Zhao et al., 2010; Zhu et al., 2012). The relationship between vegetation and microtopography has been analyzed in many countries. Sakai and Ohsawa (1993) classified 55 woody species into seven types using cluster analysis and principal coordinate analysis, and found that the seven vegetation types coincided with seven microtopographical facets at a scale of 10-100 $\mathrm{m}^{2}$. Furthermore, different species were found in different microtopography types. For instance, different floristic compositions were found on ridge slopes, surrounding slopes and landslide slopes on Mt. Kiyosumi, central Japan (Sakai and Ohsawa, 1993); more cedar was found in drier areas, whereas shrubs and hardwoods were found in wetter areas in Michigan's Upper Peninsula (Chimner and Hart, 1996); and the various habitat niches of species were related to topography in a subtropical evergreen broad-leaved forest in the north of Okinawa Island, Japan (Tsutomu, 2003). In addition, the effects of microtopography on the infiltration of rainfall on slopes in Kenya (Thomas et al., 1991; Thompson et al., 2010), the canopy distribution in Okinawa Island, Japan (Tsutomu, 2003), and tree species diversity and forest structure in a tropical freshwater swamp forest in French Guiana (Piia et al., 2004) have been investigated. Similar research has also been conducted in China. For instance, the matching relationship between the community structure of a subtropical evergreen broadleaved forest and microtopography types was analyzed in Chebaling National Nature Reserve, Guangdong (Ma et al., 2010); the differences in the sprouting traits of the Ginkgo biloba populations in different micro-landforms of Guizhou province and Chongqing municipality were reported (Yang et al., 2011); and herbaceous community characteristics were studied in the microtopography of Wuqi county, Shaanxi province (Wang et al., 2012). Though these studies provide better information on forest restoration and regeneration, they only offer qualitative descriptions and do not propose quantitative data regarding forestation, particularly about microtopography forestation. Nevertheless, spatial point pattern analysis can allow the quantification of the spatial distribution and co-occurrence patterns of the mapped positions of individual plants within a study region (Martínez et al., 2010). Different statistics have been proposed for the analysis of patterns within and between species in a scale dependent manner (Turkington and Harper, 1979). This feature of spatial point pattern analysis is important because most processes in plant communities are scale dependent (Levin, 1992; Wiegand and Moloney, 2004).

The purpose of this study was: (1) to investigate the effect of microtopography on the intra- and interspecies spatial pattern of six main tree species (Armeniaca sibirica Lam., Populus simonii Carr., Ulmus pumila Linn., Pyrus betulifolia Bunge, Robinia pseudoacacia Linn. and Populus hopeiensis $\mathrm{Hu} \&$ Chow) inhabiting sites of different microtopography types in the semi-arid Loess Plateau of China; and (2) to show that microtopography should be considered as the basic unit of forestation on microtopography slopes.

\section{Materials and methods}

\subsection{Study sites}

The study was conducted on two shady slopes, Slope A located in Yangqingchuan (36 $52^{\prime} 22^{\prime \prime}-36^{\circ} 52^{\prime} 32^{\prime \prime} \mathrm{N}$, $\left.108^{\circ} 14^{\prime} 17^{\prime \prime}-108^{\circ} 14^{\prime} 32^{\prime \prime} \mathrm{E}\right)$ and Slope B in Hegou $\left(36^{\circ} 54^{\prime} 09^{\prime \prime}-36^{\circ} 54^{\prime} 23^{\prime \prime} \mathrm{N}, 108^{\circ} 12^{\prime} 50^{\prime \prime}-108^{\circ} 13^{\prime} 01^{\prime \prime} \mathrm{E}\right)$ watersheds in Wuqi county, northern Shaanxi

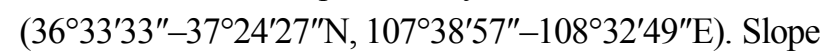
A (approximately $5 \mathrm{hm}^{2}$, calculated by ArcGIS 9.3) is a uniform slope without microtopography, and slope B (about $5 \mathrm{hm}^{2}$, calculated by ArcGIS 9.3) is composed of four microtopography types (sink hole, gully, platform and scarp; Fig. 1). The soil textures of the two slopes are nearly homogeneous at the study sites (Li and Shao, 2006). The soil moisture and nutrient distribution of slope A were uniform, but those of slope B were heterogeneous because of the microtopography (Zhang et al., 2011a, b; Zhu et al., 2012). Since the 1990s, the study sites have been undergoing conversion from cropland to forest, and some tree ( $A$. 
sibirica, U. pumila, etc.) and shrub (Hippophae rhamnoides, Caragana korshinskii, etc.) species of the same age are present. A. sibirica, P. simonii, and $U$. pumila only appear on slope $\mathrm{A}$, whereas the forest stand on slope B consists of $A$. sibirica, $P$. simonii, $U$. pumila, P. betulifolia, R. pseudoacacia, P. hopeiensis, Salix matsudana and Ailanthus altissima. Slope A is a northern slope and slope B is a northeastern slope (the average inclination for each slope is $25^{\circ}$ ), and both slopes were undisturbed during the conversion of cropland to forest. The region is characterized by a temperate continental monsoon climate that is warm and dry, with an annual mean temperature of $7.8^{\circ} \mathrm{C}$ and mean annual precipitation of $466 \mathrm{~mm}$ (based on data spanning 1957-2009). The annual variation in precipitation is large and there is an uneven distribution in different seasons, with most precipitation occurring from June to September.

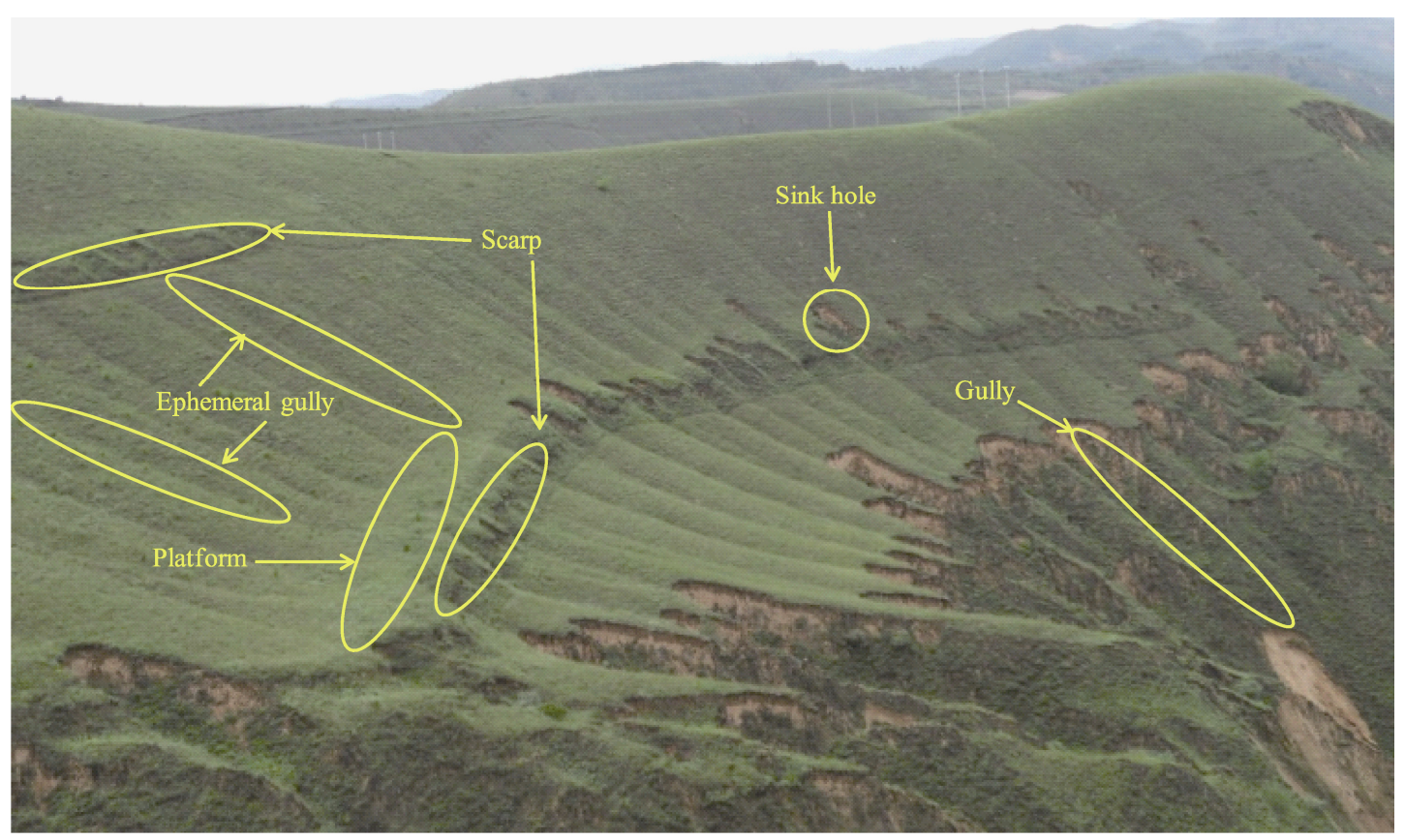

Fig. 1 Photo illustrating microtopography, including gully, sink hole, platform, scarp and ephemeral gully, on the slope of the Hegou watershed

\subsection{Microtopography}

Previously, microtopography was defined as the change in topography at a small scale, and it was divided into the seven units of crest slope, upper side slope, head hollow, lower side slope, foot slope, flood terrace and riverbed by Nagamatsu and Miura (1997). The microtopography types were also classified into three units (hummock, pool and intermediate area) by Chimner and Hart (1996). The definition and types of microtopography are not in complete accord with each other. In this study, the definition of microtopography is a local terrain of different sizes and shapes resulted from soil erosion, leading to the variation of habitat conditions such as soil moisture and nutrients within $1 \mathrm{~m}^{2}$ or more (Wang et al., 2011; Zhu et al., 2012). Meanwhile, the types of microtopography consist of platform, gully, sink hole, scarp and ephemeral gully (Fig. 1) (Zhao et al., 2010; Wang et al., 2011). In addition, previous studies showed that the soil moisture and nutrient contents in the sink hole, platform and gully were higher than those in scarp and ephemeral gully (Lu et al., 2009; Zhao et al., 2010; Wang et al., 2011; Zhang et al., 2011a, b).

\subsection{Data collection}

In July 2012, we surveyed every adult tree (individuals with a height greater than $1 \mathrm{~m}$ ) within the study sites, and recorded their location ( $x, y$ coordinates), elevation, height, diameter at breast height (DBH; 1.3 $\mathrm{m}$ above ground) and microtopography type. We collected the coordinates and elevations of all trees using a GPS, measured the heights using a Blume-Leiss hypsometer, and obtained the DBH using a diameter 
tape. This information was then added to a geographic information system (GIS), and a database was created. The locations of all the adult trees were mapped by the GIS (Fig. 2). The final data consist of the coordinates,
DBH, height, species identity and growth conditions (microtopography type or uniform slope) of each individual tree. Table 1 presents the sample sizes and basic information for the studied species.
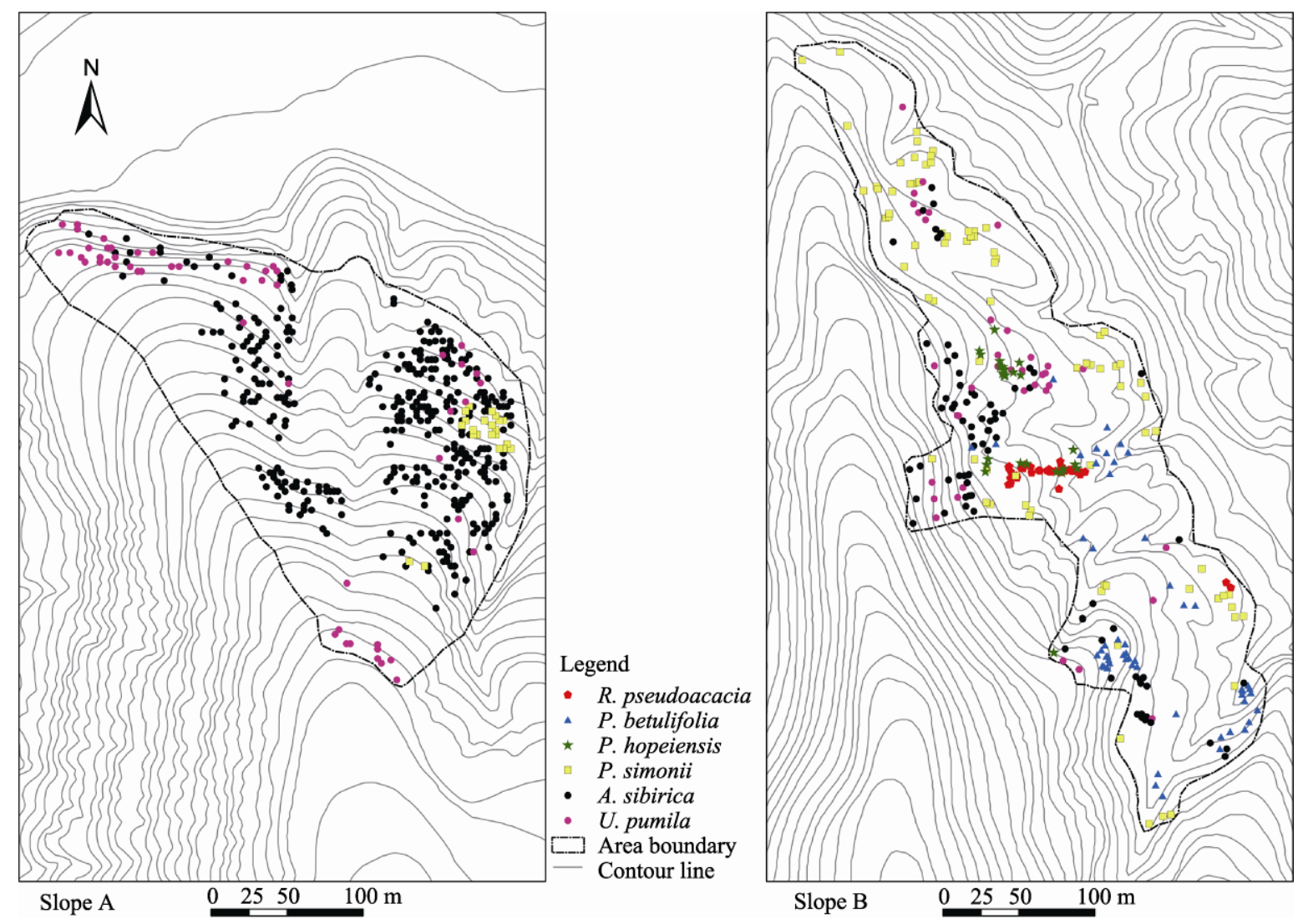

Fig. 2 Maps illustrating the locations of all adult trees in slope A and B

\subsection{Data analysis}

\subsubsection{Univariate spatial pattern}

Ripley's $K(r)$ function was used to analyze the observed mapped point patterns of trees in each stand (Ripley, 1976, 1981). The unbiased univariate estimator of the $K$-function for exploring univariate spatial pattern is:

$$
K(r)=n^{-2}|A| \sum_{i \neq j} \sum w_{i j}^{-1} I_{r}\left(d_{i j}\right) .
$$

Where $n$ is the total number of trees in study site $\mathrm{A} ; d_{i j}$ is the distance between the $i^{\text {th }}$ (focal) tree and the $j^{\text {th }}$ (neighboring) tree; $I_{r}\left(d_{i j}\right)$ is an indicator function, equaling 1 if $d_{i j}<r$ and 0 otherwise; $w_{i j}$ is included to correct for the edge effect, and it equals the proportion of the circumference of a circle centered at the $i^{\text {th }}$ tree with radius $d_{i j}$ ( $w_{i j}$ is 1 if the entire circumference of the circle lies within A). To ensure sufficient neighboring pairs for constructing the $K$-function, the function was computed at a $1.0 \mathrm{~m}$ interval with distance $r \leq 100 \mathrm{~m}$ (slope-scale).

The variance reduction form of the $K$-function,

$$
L(r)=K(r)^{0.5} \pi^{-0.5}-r,
$$

was used to compare the observed spatial patterns of each dominant tree species in each successional phase against a random pattern. $L(r)=0$ for complete spatial randomness (CSR), $L(r)>0$ for an aggregated pattern, whereas $L(r)<0$ for a regular pattern.

\subsubsection{Bivariate spatial association}

Bivariate spatial association is the spatial point pattern of two tree species (i.e. multiple point pattern analysis). 


\begin{tabular}{|c|c|c|c|c|c|c|}
\hline & \multicolumn{6}{|c|}{ Species } \\
\hline & A. sibirica & P. simonii & U. pumila & P. betulifolia & R. pseudoacacia & P. hopeiensis \\
\hline Location & Slope A/Slope B & Slope A/Slope B & Slope A/Slope B & Slope B & Slope B & Slope B \\
\hline Microtopography & $\begin{array}{l}\text { Uniform slope/Platform, } \\
\text { sink hole, unrolling slope }\end{array}$ & $\begin{array}{l}\text { Uniform slope/Platform, } \\
\text { gully, unrolling slope }\end{array}$ & $\begin{array}{l}\text { Uniform slope/Scarp, } \\
\text { unrolling slope }\end{array}$ & $\begin{array}{l}\text { Gully, platform, } \\
\text { unrolling slope }\end{array}$ & Gully & $\begin{array}{c}\text { Unrolling } \\
\text { slope, platform, } \\
\text { gully }\end{array}$ \\
\hline$n$ total & $392 / 31,27,20$ & $22 / 35,23,23$ & $55 / 28,10$ & $21,18,15$ & 45 & $9,8,8$ \\
\hline \multicolumn{7}{|l|}{ DBH (cm) } \\
\hline Maximum & $38.5 / 30.0$ & $48.2 / 47.0$ & $39.4 / 32.0$ & 35.0 & 18.0 & 38.0 \\
\hline Minimum & $1.9 / 5.0$ & $14.9 / 7.0$ & $7.1 / 3.0$ & 6.0 & 9.0 & 6.0 \\
\hline Mean & $15.9 / 17.5$ & $24.8 / 26.7$ & $14.6 / 13.6$ & 20.3 & 11.7 & 14.9 \\
\hline SD & $6.7 / 5.9$ & $8.4 / 6.8$ & $7.2 / 6.4$ & 5.4 & 3.0 & 8.5 \\
\hline Skewness & $0.44 / 0.148$ & $1.03 / 0.164$ & $1.17 / 0.858$ & -0.149 & 0.913 & 1.453 \\
\hline \multicolumn{7}{|l|}{ Height (m) } \\
\hline Maximum & $9.2 / 10.2$ & $15.2 / 27.5$ & $10.1 / 6.8$ & 11.4 & 8.5 & 17.1 \\
\hline Minimum & $2.1 / 2.8$ & $1.4 / 4.8$ & $1.7 / 1.5$ & 3.0 & 4.5 & 6.0 \\
\hline Mean & $5.5 / 5.8$ & $8.1 / 12.6$ & $4.5 / 4.0$ & 6.5 & 6.3 & 10.3 \\
\hline SD & $1.5 / 1.4$ & $4.0 / 4.5$ & $1.7 / 1.3$ & 1.9 & 1.6 & 2.6 \\
\hline Skewness & $-0.22 / 0.36$ & $-0.44 / 1.148$ & $0.677 / 0.181$ & 0.451 & -0.107 & 1.092 \\
\hline
\end{tabular}

Note: Slope A, uniform slope; Slope B, microtopography slope. The microtopography sequence is homologous with $n$ total.

The second-order bivariate estimator of Ripley's $K$-function was defined for exploring interspecies competition as:

$$
K_{12}(r)=\left(n_{1} n_{2}\right)^{-1}|A| \sum_{i=1}^{n_{1}} \sum_{j=1}^{n_{2}} w_{i j}^{-1} I_{r}\left(d_{i j}\right)
$$

where $n_{1}$ and $n_{2}$ are the total number of trees of species 1 and 2 that occur in site $A$; other terms are the same as for Eq. 1.

The variance reduction bivariate transformation of $K_{12}(r)$ (Lotwick and Silverman, 1982) is:

$$
L_{12}(r)=K_{12}(r)^{0.5} \pi^{-0.5}-r \text {. }
$$

If species 1 and 2 are randomly associated, $L_{12}(r)=0$; if the two species are positively associated, $L_{12}(r)>0$; if they are negatively associated, $L_{12}(r)<0$.

\subsubsection{Monte Carlo simulation inspection}

To evaluate the significance level of non-CSR, the observed $L$-functions for the spatial pattern of each tree species and the interspecies spatial association at the two scales were compared to the intervals generated by the Monte Carlo simulation of random location selection, where the relative coordinates for the same number of trees were randomly generated.

In these intraspecies pattern analyses, if $L(r)$ at a distance $r$ is above the upper limit of the confidence interval, the intraspecies pattern is defined as an aggre- gated pattern; if $L(r)$ is below the lower limit of the confidence interval, it is defined as a regular pattern; and if $L(r)$ lies between the upper and lower limits of the confidence interval, it is CSR. In interspecies spatial association analyses, if $L_{12}(r)$ is above the upper (or below the lower) limit of the confidence envelope, pattern 2 is positively (or negatively) associated with pattern 1 at distance $r$ (Hao et al., 2007); and if $L_{12}(r)$ is within the upper and lower limits of the confidence envelope, there is no association between patterns 1 and 2. The Monte Carlo simulation was repeated 99 times and an $L$-function was calculated each time. The second to minimum and second to maximum $L(r)$ at each distance $r$ were used as the $99 \%$ Monte Carlo interval for each given $r$. The $L(r)$ function statistics were computed using ADE-4 software.

Subsequently, we obtained the intraspecies spatial patterns and interspecies spatial association for the uniform slope and the patterns for the microtopography slope.

\section{Results}

\subsection{Univariate spatial patterns}

2.1.1 Univariate spatial patterns on the uniform slope An analysis of the tree species spatial distribution on 
slope A revealed a predominant spatial aggregation pattern for A. sibirica, $P$. simonii and $U$. pumila at the scale of $0-100 \mathrm{~m}$ (Fig. 3). The observed spatial pattern curve of $A$. sibirica exhibited an inverted J-shape and reached the maximal aggregation radius at $r=70 \mathrm{~m}$; however, the spatial pattern curves of $P$. simonii and $U$. pumila were unimodal and achieved peaks at $r=28$ and $40 \mathrm{~m}$, respectively. In addition, the aggregation intensities of $A$. sibirica and U. pumila were less than 49, whereas that of $P$. simonii was 128.
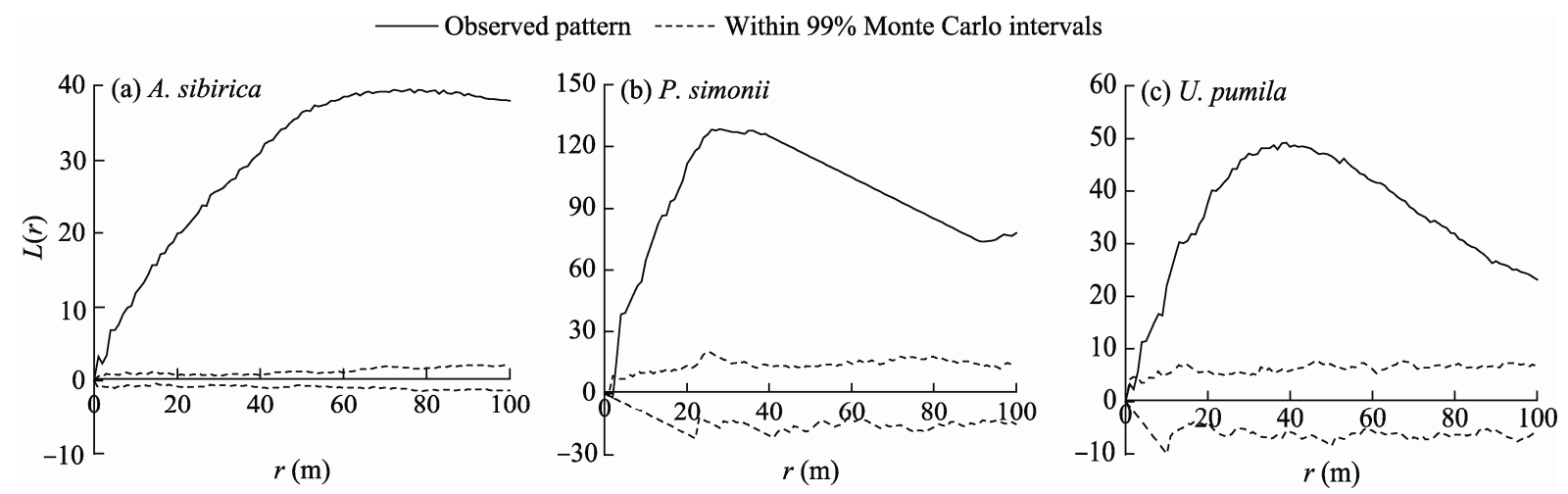

Fig. 3 Univariate spatial pattern analyses of the tree species on slope A. $L(r)$, intraspecies spatial pattern; $r$, spatial scale. The same below.

2.1.2 Univariate spatial patterns on the microtopography slope

All the spatial pattern curves were unimodal on slope B (Fig. 4). Only the spatial pattern of R. pseudoacacia showed an aggregation distribution at the scale of 0-100 $\mathrm{m}$; however, the spatial patterns of the other tree species displayed aggregation distributions at small scales.

Although the spatial pattern of $R$. pseudoacacia showed aggregation distribution at $0-100 \mathrm{~m}$, its maximal aggregation radius was reached at $29 \mathrm{~m}$ (Fig. 4a). The observed $L(r)$ of $P$. betulifolia fell within the Monte Carlo interval at a scale of up to $12 \mathrm{~m}$ and started at $28 \mathrm{~m}$, indicating a random distribution; however, it showed aggregation at $12-28 \mathrm{~m}$ and reached the maximal aggregation radius at $15 \mathrm{~m}$ (Fig. 4b). P. hopeiensis was aggregated at 5-64 $\mathrm{m}$, and randomly distributed at $0-5$ and $64-100 \mathrm{~m}$, with a maximal aggregation radius of $29 \mathrm{~m}$ (Fig. 4c). A. sibirica showed an aggregation distribution at $0-30 \mathrm{~m}$ and random distribution at $30-100 \mathrm{~m}$ with the maximal aggregated radius at $13 \mathrm{~m}$ (Fig. $4 \mathrm{~d})$. P. simonii shifted from aggregation at $0-54 \mathrm{~m}$ to random distribution at 54-100 $\mathrm{m}$ and reached the maximal aggregated radius at $22 \mathrm{~m}$ (Fig. 4e). However, U. pumila was randomly distributed on the scale of $0-15 \mathrm{~m}$ and
45-100 $\mathrm{m}$ and aggregated at 15-45 $\mathrm{m}$ with a maximal aggregated radius of $20 \mathrm{~m}$. The maximum aggregation intensities of all the tree species were simultaneously larger than 50 (Fig. 4f), and ranged from 50 to 80 on the microtopography slope.

\subsection{Bivariate spatial patterns of dominant tree species}

2.2.1 Bivariate spatial patterns on the uniform slope The observed $L_{12}(r)$ function for $A$. sibirica and $P$. simonii fell within the Monte Carlo interval at 0-20 and $47-78 \mathrm{~m}$, indicating that there was no significant spatial association, only shifting to slightly significant, positive spatial association at the scales of $20-47$ and 78-100 m, respectively. Nevertheless, the tree species pair of $U$. pumila and A. sibirica showed highly significant, negative spatial association, as well as the tree species pair of $U$. pumila and P. simonii at $0-100$ m (Fig. 5).

2.2.2 Bivariate spatial patterns on the microtopography slope

In contrast to slope $\mathrm{A}$, all the spatial associations of interspecies pairs on slope B exhibited from significantly negative spatial association to significantly positive association or no spatial association as the scale increased from 0 to $100 \mathrm{~m}$ (Fig. 6). The trend 

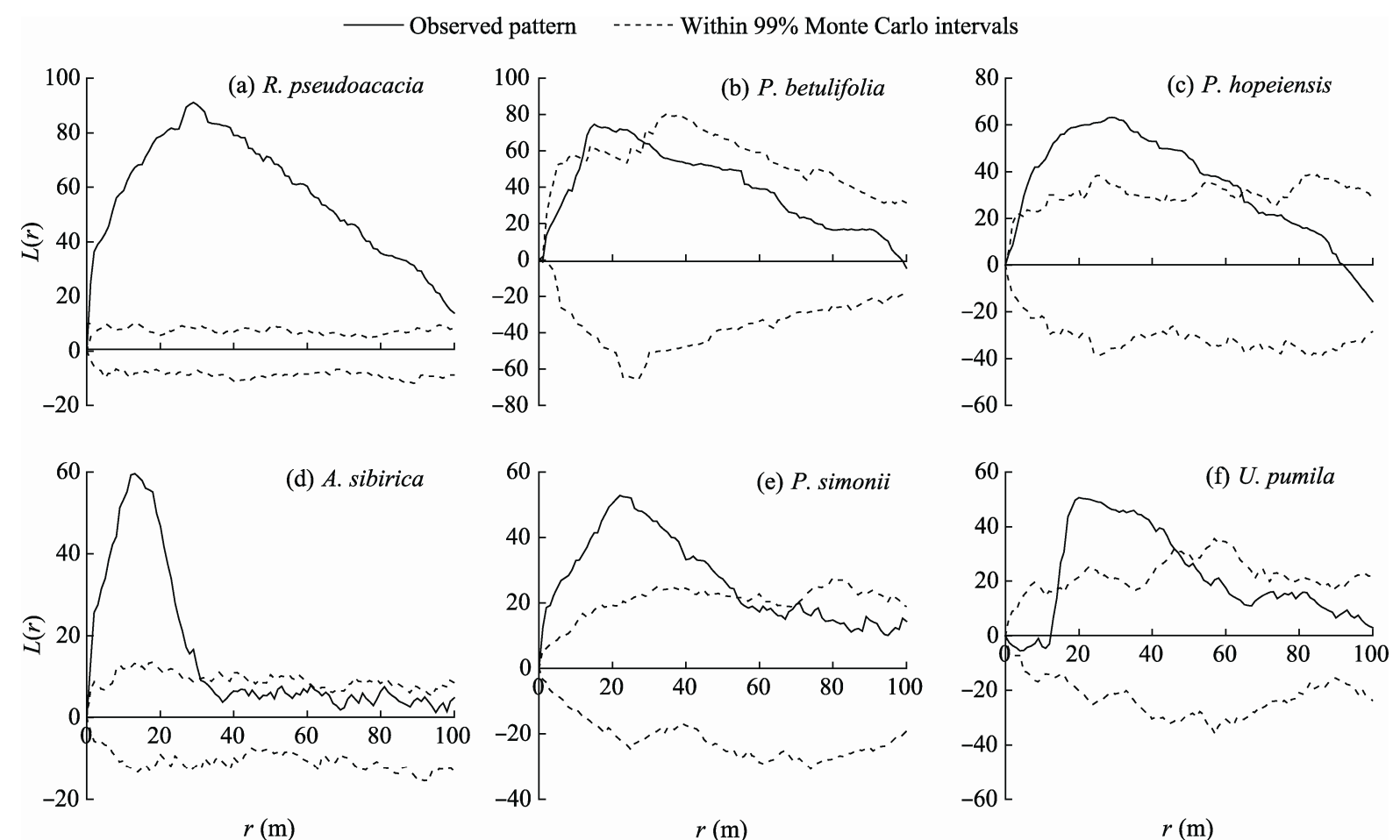

Fig. 4 Univariate spatial pattern analyses of the tree species on slope B - Observed pattern ------ Within 99\% Monte Carlo intervals
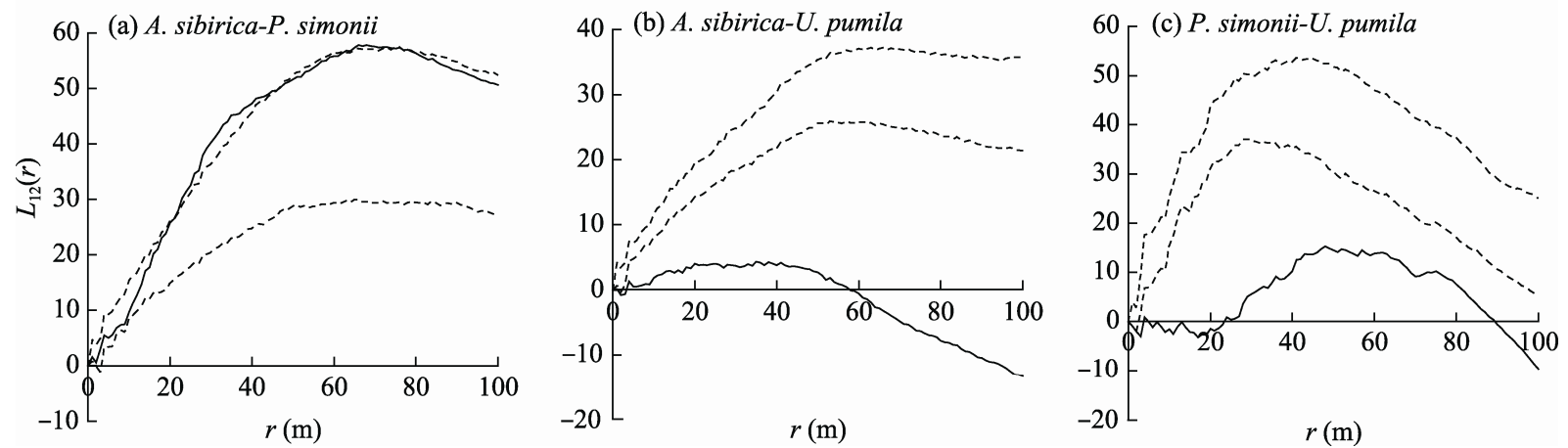

Fig. 5 Bivariate analyses exploring the spatial association of a given species with all other species on slope $A$ at the scale of $0-100 \mathrm{~m}$

revealed that the interspecies competition changed from intense to slight on slope B. Particularly, A. sibirica and $P$. simonii showed significantly negative spatial association at $0-13 \mathrm{~m}$ and shifted to no significant spatial association at $13-100 \mathrm{~m}$ (Fig. 6m). However, A. sibirica and $U$. pumila showed no significant spatial association at $0-100 \mathrm{~m}$ (Fig. 6n). $P$. simonii maintained the strongest negative spatial association with $U$. pumila at $13-31 \mathrm{~m}$, with indistinct spatial association at $0-13 \mathrm{~m}$ and $31-100 \mathrm{~m}$ (Fig. 6o). This suggests that microtopography reduced interspe- cies competition intensity to some extent and increased the number of tree species available for nearnatural forestation.

\section{Discussion}

Exploring intraspecies and interspecies spatial associations can elucidate the effects of diverse microtopography types on microtopography forestation and management regimes (Lacambra et al., 2012; Zhang et al., 2012). The Loess Plateau was divided into six ecological regions based on different soil moisture 

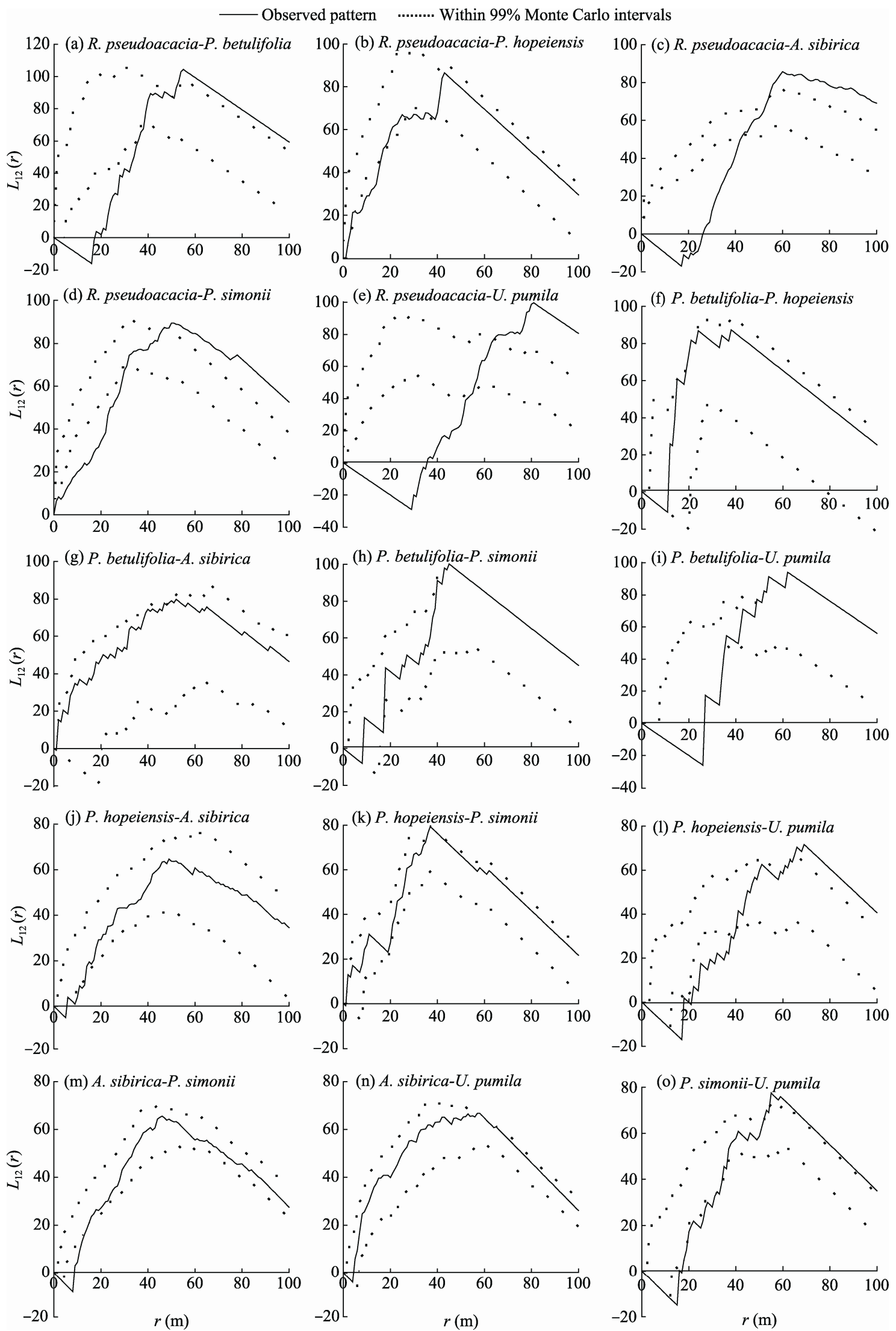

Fig. 6 Bivariate analyses exploring the spatial associations of the given species with all other species on slope B at the scale of 0-100 m 
conditions for afforestation, and vegetation configuration models were proposed for the six regions (Yang et al., 1994). Subsequently, vegetation configuration models were adjusted by the loess slope, the gully slope, the top of the loess hill and the gully bottom according to the distribution of soil moisture, fertility as well as the sunlight and temperature on the slope (Ren et al., 2001). The traditional forestation model used uniform planting points with the same row spacing along the contours based on the site conditions of the slopes (Zou et al., 1980; Zhu et al., 2012), but did not take into account the catchment effect of microtopography (Li et al., 2011; Wang et al., 2011). Considering microtopography types as the basic forestation units produced different conclusions from the traditional model used for the Loess Plateau.

\subsection{Intraspecies spatial patterns}

The spatial distribution pattern of tree populations is closely related to the spatial scale (Lai et al., 2010). Manabe et al. (2000) proposed that the spatial pattern and spatial association pattern of tree species may be affected by intraspecies competition and the method of seed dispersal at smaller scales, whereas at larger scales, they may be determined by the heterogeneity or patchiness of the species distribution and different environmental conditions (such as terrain and soil moisture). In our study, the slope scales $\left(5 \mathrm{hm}^{2}\right)$ were large, and the topographical characteristics of the microtopography affected the redistribution of soil moisture and nutrients (Zhao et al., 2010; Wang et al., 2011; Zhu et al., 2012). Therefore, the intraspecies spatial patterns of the species in our study were different for different microtopographies. The spatial pattern of R. pseudoacacia showed aggregated distribution at $0-100 \mathrm{~m}$ and all individuals lived in the gully on slope $\mathrm{B}$, because this species does not like wind and the soil moisture of the gully was greater than that of the other microtopographies (Wang et al., 2012). So the intraspecies competition of $R$. pseudoacacia was weaker. The spatial distribution pattern of the other tree species varied from random to aggregated distribution, and then reverted to random distribution. This was mainly because there were few individuals when the scale was smaller, whereas several tree species formed patches (aggregated distribution) following the shape of the microtopography types on the microtopography scale. Nevertheless, when the scale was larger than the microtopography scale, the soil moisture and nutrients of the slope were unevenly distributed, and the conditions of soil moisture and nutrients were better in the microtopography for the growth of tree species (Wang et al., 2011; Zhang et al., 2011a, b). Therefore, the intraspecies competition gradually became stronger, and the spatial distribution pattern changed from aggregated to random distribution. But the largest aggregated radiuses were less than $30 \mathrm{~m}$. However, the intraspecies spatial distribution showed weaker competition and slight aggregation, and the maximum aggregated radiuses of the tree species were larger than $30 \mathrm{~m}$, because of the uniform distribution of soil moisture and nutrients in slope A. In previous studies, the intraspecies spatial pattern also changed as the habitat conditions, such as terrain and soil moisture, varied (Richard Condit et al., 2000; Caillaud et al., 2010; Liu et al., 2012).

Therefore, the univariate spatial patterns of tree species in slope A and slope B may indicate that the effect of microtopographical factors on the intraspecies spatial distribution of all tree species on slope B was greater than intraspecies competition, because of the difference in the univariate spatial pattern between slopes A and $\mathrm{B}$. The maximum aggregated radiuses for slope $\mathrm{B}$ were less than $30 \mathrm{~m}$, yet those for slope A were larger than $28 \mathrm{~m}$. This indicates that all the trees were arranged in small clumps in slope B. However, the aggregation intensities of all the tree species in slope $\mathrm{B}$ were larger than that of $A$. sibirica and U. pumila in slope A. These results also confirm that microtopography types should determine the choice of tree species for near-natural forestation.

\subsection{Interspecies spatial associations}

The interspecies spatial association patterns at a community-wide scale revealed that microtopography affected the bivariate spatial patterns and supported the mixed afforestation models on the microtopography slope at the scale of $0-100 \mathrm{~m}$. For example, the species pairs, such as $P$. betulifolia and $P$. hopeiensis, $P$. betulifolia and A. sibirica, P. betulifolia and P. simonii, $P$. betulifolia and U. pumila, P. hopeiensis and A. sibirica, $P$. hopeiensis and $P$. simonii, $A$. sibirica and $P$. simonii, and A. sibirica and U. pumilathe, could be considered as mixed afforestation. However, 
the interspecies competition between R. pseudoacacia and the other tree species changed from strong to weak as the scale increased, because the $R$. pseudoacacia individuals were distributed in the gully at the scale of approximately $30 \mathrm{~m}$. Similarly, U. pumila and $P$. hopeiensis, and U. pumila and P. simonii also displayed a similar spatial association pattern, because the $U$. pumila individuals lived on the scarp and had a preference for full sunlight. However, they were shorter than the other tree species individuals (except R. pseudoacacia), and various species individuals inhibited each other. Franklin et al. (2002) and North et al. (2004) compared species composition, structure, spatial pattern and environmental factors (such as light and soil moisture) between two old-growth forests in the Pacific Northwest and southern Sierra Nevada, respectively. They found that the bivariate spatial patterns were influenced by higher moisture, shade tolerance, scale and topography. In addition, $\mathrm{Li}$ et al. (2011) found that the spatial associations of different strata were affected by the spatial scale and forest stand strata in a Schrenk Spruce forest of Northwest China. The results of all the above studies are similar to those of this study.

However, for the uniform slope A, A. sibirica was the main species, with fewer $P$. simonii and U. pumila individuals present. Because $P$. simonii individuals formed clumps and lived in the gaps of $A$. sibirica, the spatial association of $P$. simonii with $A$. sibirica was not strongly negative at the scale of $0-100 \mathrm{~m}$. However, the spatial associations of $U$. pumila with $A$. sibirica, and $U$. pumila with $P$. simonii were strongly negative at the scale of $0-100 \mathrm{~m}$, which may be due to the photophilic characteristics of $U$. pumila (Liu et al., 2012).

\section{Conclusions}

The use of spatial point pattern analysis is a complementary approach to the experimental study of plant communities at the level of species individuals. In this study area, microhabitats created by microtopography affected the intraspecies spatial pattern and the interspecies spatial association of tree species. The slope microtopography led to aggregated distribution of all tree species on the smaller scale and resulted in changes from significantly negative association to significantly positive association for the tree species pairs. The results of this study show that microtopography plays an important role in near-natural forestation, particularly in the fragmented semi-arid area of China. More importantly, microtopography, including artificial microtopography, should be considered as the basic unit in afforestation to speed up the ecological restoration in semi-arid areas.

\section{Acknowledgments}

The study was financially supported by China National Scientific and Technical Innovation Research Project for $12^{\text {th }}$ Five Year Plan (2011BAD38B0601), the National Natural Science Foundation of China (41472313) and the Natural Science Foundation of Shandong Province (ZR2011DM012, ZR2014DL002). The authors would like to extend their sincere gratitude to ZongKai WU and GuangLiang LIU for their help in providing local support during the study.

\section{References}

Caillaud D, Crofoot M C, Scarpino S V, et al. 2010. Modeling the spatial distribution and fruiting pattern of a key tree species in a neotropical forest: methodology and potential applications. PLoS ONE, 5: e15002.

Chimner R A, Hart J B. 1996. Hydrology and microtopography effects on northern white-cedar regeneration in Michigan's Upper Peninsula. Canadian Journal of Forest Research, 26: 389-393.

Condit R, Ashton P S, Baker P, et al. 2000. Spatial patterns in the distribution of tropical tree species. Science, 288: 1414-1418.

Franklin J F, Spies T A, Van Pelt R, et al. 2002. Disturbances and structural development of natural forest ecosystems with silvicultural implications, using Douglas-fir forests as an example. Forest Ecology and Management, 155(1-3): 399-423.

Hao Z Q, Zhang J, Song B, et al. 2007. Vertical structure and spatial associations of dominant tree species in an old-growth temperate forest. Forest Ecology and Management, 252(1-3): 1-11.

Lacambra L C J, Martín A G, Roberto S M F. 2012. Effects of microsite conditions and early pruning on growth and health status of holm oak plantations in Central-Western Spain. New Forests, 43(5): 887-903.

Lai J S, Mi X C, Ren H B, et al. 2010. Numerical classification of associations in subtropical evergreen broad-leaved forest based on multivariate regression trees-a case study of $24 \mathrm{hm}^{2}$ Gutianshan forest plot in China. Chinese Journal of Plant Ecology, 34: 761-769. (in Chinese)

Levin S A. 1992. The problem of pattern and scale in ecology: the Robert H. MacArthur Award Lecture. Ecology, 73(6): 1943-1967.

Li M H, He F H, Pan C D. 2011. Spatial distribution pattern of different strata and spatial assocations of different strata in the Schrenk Spruce forest, northwest China. Acta Ecologica Sinica, 31(3): 620-628. (in Chinese)

Li P, Zhu Q K, Zhao L L, et al. 2011. Soil moisture of fish-scale pit during rainy season in Loess hilly and gully region. Transactions of 
the CSAE, 27(7): 76-81. (in Chinese)

Li Y Y, Shao M A. 2006. Change of soil physical properties under long-term natural vegetation restoration in the Loess Plateau of China. Journal of Arid Environments, 64(1): 77-96.

Liu Z, Li H L, Dong Z, et al. 2012. The spatial point pattern of Ulmus pumila population in two habitats in the otindag sandy land. Scientia Silvae Sinicae, 48(1): 29-34. (in Chinese)

Lotwick H W, Silverman B W. 1982. Methods for analysing spatial processes of several types of points. Journal of the Royal Statistical Society: Series B (Methodological), 44(3): 406-413.

Lu B C, Xue Z D, Zhu Q K, et al. 2009. Soil water in micro-terrain on sunny and semi-sunny slopes. Bulletin of Soil and Water Conservation, 29(1): 62-65. (in Chinese)

Ma X D, Zhang S J, Su Z Y, et al. 2010. Community structure in relation to microtopography in a montane evergreen broadleaved forest in Che baling National Nature Reserve. Acta Ecologica Sinica, 30(19): 5151-5160. (in Chinese)

Manabe T, Nishimura N, Miura M, et al. 2000. Population structure and spatial patterns for trees in a temperate old-growth evergreen broad-leaved forest in Japan. Plant Ecology, 151: 181-197.

Martínez I, Wiegand T, González-Taboada F, et al. 2010. Spatial associations among tree species in a temperate forest community in North-western Spain. Forest Ecology and Management, 260(4): 456-465.

Nagamatsu D, Miura O. 1997. Soil disturbance regime in relation to micro-scale landforms and its effects on vegetation structure in a hilly area in Japan. Plant Ecology, 133(2): 191-200.

North M, Chen J, Oakley B, et al. 2004. Forest stand structure and pattern of old-growth western hemlock/Douglas-fir and mixed-conifer forests. Forest Science, 50(3): 299-311.

Piia K, Pekka N, Daniel S, et al. 2004. Tree species diversity and forest structure in relation to microtopography in a tropical freshwater swamp forest in French Guiana. Plant Ecology, 173(1): 17-32.

Ren Y J, Zhao G Y, Li J L, et al. 2001. Disposition model of grass and forest in slope land of loess plateau in third sub-region. Journal of Soil and Water Conservation, 15(6): 78-80. (in Chinese)

Ripley B D. 1976. The second-order analysis of stationary point processes. Journal of Applied Probability, 13(2): 255-266.

Ripley B D. 1981. Spatial Statistics. New York: Wiley.

Sakai A, Ohsawa M. 1993. Vegetation pattern and microtopography on a landslide scar of Mt Kiyosumi, central Japan. Ecological Research, 8(1): 47-56.

Thomas D, Zhang W H, Brian F A. 1991. Effects of rainfall vegetation and microtopography on infiltration and runoff. Water Resources Research, 27(9): 2271-2285.

Thompson S E, Katul G G, Porporato A. 2010. Role of microtopography in rainfall-runoff partitioning: an analysis using idealized geometry. Water Resources Research, 46(7): W7520.

Tsutomu E. 2003. Microtopography and distribution of canopy trees in a subtropical evergreen broad-leaved forest in the northern part of Okinawa Island, Japan. Ecological Research, 18: 103-113.
Turkington R, Harper J L. 1979. The growth, distribution and neighbour relationships of Trifolium repens in a permanent pasture. I. Ordination, pattern and contact. Journal of Ecology, 67(1): 201-218.

Wang J, Zhu Q K, Zhao H, et al. 2011. Soil moisture characteristics of micro-topography in south slope of Loess Region in northern Shaanxi Province. Bulletin of Soil and Water Conservation, 31(4): 16-21. (in Chinese)

Wang J, Zhu Q K, Qin W, et al. 2012. Differentiation of vegetation characteristics on slope micro-topography of fenced watershed in loess area of north Shaanxi province, Northwest China. Chinese Journal of Applied Ecology, 23(3): 694-700. (in Chinese)

Wang L, Wei S P, Wu F Q. 2009. Soil water environment and vegetation growth in the hilly and gully region of the Loess Plateau: a case study of Yangou Catchment. Acta Ecologica Sinica, 29(3): 1543-1553. (in Chinese)

Wiegand T, Moloney K A. 2004. Rings, circles, and null-models for point pattern analysis in ecology. Oikos, 104(2): 209-229.

Yang J W, Liang Z S, Han R L. 2006. Water use efficiency characteristics of four tree species under different soil water conditions in the Loess Plateau. Acta Ecologica Sinica, 26(2): 558-565. (in Chinese)

Yang W Z, Ma Y X, Han S F, et al. 1994. Soil water ecological regionalization of afforestation in Loess Plateau. Journal of Soil and Water Conservation, 8(1): 1-9. (in Chinese)

Yang Y C, Mu J P, Tang C Q, et al. 2011. Community structure and population regeneration in remnant Ginkgo biloba stands. Acta Ecologica Sinica, 31(21): 6396-6409. (in Chinese)

Zhang H Z, Zhu Q K, Wang J, et al. 2011a. Soil physical properties of micro-topography on loess slope in North Shaanxi Province. Bulletin of Soil and Water Conservation, 31(6): 55-58. (in Chinese)

Zhang H Z, Zhu Q K, Zhao L L, et al. 2011b. Soil chemical properties of micro-topography on loess slope in Northern Shaanxi Province. Science of Soil and Water Conservation, 9(5): 20-25. (in Chinese)

Zhang Y T, Li J M, Chang S L, et al. 2012. Spatial distribution pattern of Picea schrenkiana population in the Middle Tianshan Mountains and the relationship with topographic attributes. Journal of Arid Land, 4(4): 457-468.

Zhao H, Zhu Q K, Qin W, et al. 2010. Soil moisture characteristics on microrelief of dry south-slope on the Loess Plateau. Bulletin of Soil and Water Conservation, 30(3): 64-68. (in Chinese)

Zhu Q K. 1988. Study on type of site factors of hillsides closed to afforest in southern Shaanxi Province using fuzzy cluster by progressive modification from centre. Bulletin of Soil and Water Conservation, 8(5): 30-34. (in Chinese)

Zhu Q K, Zhang Y, Zhao L L, et al. 2012. Vegetation Restoration and Simulated Natural Forestation in the Loess Plateau, Northern Shaanxi, China. Beijing: Science Press. (in Chinese)

Zou H Y, Liang Y M, Sun J T. 1980. A preliminary study on vegetation regionalism in Loess Plateau of the North Shaanxi Province. Acta Botanica Sinica, 22(4): 399-401. (in Chinese) 